\title{
ENTRE EL EDIFICIO Y EL CURRÍCULUM DE LA INTERCULTURALIDAD: UNA MIRADA ANTROPOLÓGICA A LA EDUCACIÓN ACTUAL EN TERRITORIO MAPUCHE-HUILLICHE
}

\author{
BETWEEN THE BUILDING AND THE CURRICULUM OF INTERCULTURALITY: \\ AN ANTHROPOLOGICAL VIEW OF PRESENT EDUCATION IN \\ MAPUCHE-HUILLICHE TERRITORY
}

\author{
Amilcar Forno ${ }^{1}$, Pilar Alvarez-Santullano ${ }^{2}$ y Rita Rivera ${ }^{3}$
}

\begin{abstract}
Este estudio es un acercamiento en perspectiva etnográfica y crítica a la construcción social de la educación intercultural bilingüe en contextos mapuche-huilliches. Nuestra mirada recoge y se centra en la red de prácticas discursivas y no discursivas que forman parte de la instalación de la educación intercultural y que generan a la vez otras respuestas, otros discursos, transformados en periféricos por lo global, lo urbano, por imposiciones tanto en el plano político y administrativo como en lo agrario, forestal, industrial y educativo.

Desde este espacio rural e indígena, que se auto-percibe colonizado, reiteradamente intervenido y transformado, surgen tensiones y se generan acciones de resistencia y contradesarrollo. En este contexto advertimos que el modelo arquitectónico de lo urbano, que se va configurando a través de las nuevas edificaciones escolares, representa una alegoría de la conformación de un currículum estatalizado, caracterizado por su linealidad, centralismo y objetivo homogeneizador.
\end{abstract}

Palabras claves: educación intercultural bilingüe, discurso, mapuche-huilliche.

This study approaches the social construction of bilingual-intercultural education within Mapuche-Huilliche contexts from an ethnographic and critical perspective. Our view picks up and focuses on the network of discursive and non-discursive practices, as part of the installation of intercultural education which, at the same time, generates other responses and other discourses transformed into peripheral issues by both the global and urban sides, and the pressures of political, administrative, agrarian, forestry, industrial and educational levels.

From this rural and indigenous space which is self-perceived as colonized, repeatedly controlled and transformed, tensions, resistance actions and counter- development actions are generated. Within this context we have further noticed that the urban architectural model that is being configured through new school buildings represents an allegory of a state curriculum characterized by its linearity, centralism and homogenizing goal.

Key words: Intercultural bilingual education, discourse, Mapuche-Huilliche.

La educación intercultural bilingüe (EIB) en Chile se instala como política estatal en contextos rurales indígenas a partir de la última década del siglo XX. Como en otros países de América Latina esta propuesta educativa parte por plantearse cuál es la educación que los pueblos originarios deberían tener en el marco de los actuales estados nacionales, caracterizados, entre otros aspectos, por un crecimiento muy importante de las organizaciones indígenas, por la construcción de procesos democráticos y con un marco de derecho internacional y nacional que, en general, avala los procesos reivindicativos de los pueblos indígenas. La EIB surge en nuestro país en este complejo contexto y si bien parte como posible respuesta a las demandas indígenas de educación, en su institucionalización termina por someter y condicionar espacios y discursos -construidos y posibles-a los lineamientos de las políticas estatales, implementadas en una primera instancia a través de planes pilotos y la estructuración del Programa de EIB del Ministerio de Educación (PEIB) y reforzadas más tarde por la creación del Programa Orígenes con inclusión de fondos internacionales del BID ${ }^{1}$.

\footnotetext{
$1 \quad$ Programa de Estudios Indígenas e Interculturales, Universidad de Los Lagos, Chile. Casilla 933 Osorno, Chile. aforno@ulagos.cl

2 Departamento de Humanidades y Arte, Universidad de Los Lagos, Osorno, Chile. palvarez@ulagos.cl

3 Departamento de Educación, Universidad de Los Lagos, Osorno, Chile. rriveraf@ulagos.cl
} 
Formulada en el contexto del modelo neoliberal del Estado chileno, los lineamientos de la intervención estatal en EIB pueden situarse en las "teorías del consenso educacional" (Gvirtz et al. 2007:67) desarrolladas a partir de la segunda mitad del siglo XX. Estas teorías agrupan a diversas corrientes educacionales, pero de manera general, todas ellas enfatizan la funcionalidad de la educación en pro del desarrollo, así como la necesidad de una planificación centralizada y altamente técnica para el logro de la eficiencia al interior de la escuela y en los resultados del macrosistema.

\section{La EIB como Dispositivo de la Modernidad}

Como señalan Gvirtz et al. (2007), las diversas corrientes de las teorías del consenso en educación se han fundado tanto en la sociología como en la economía, influencia que también resulta evidente -por la relación establecida entre pobreza y rendimiento- en el programa técnico-político de educación intercultural explicitado por el Ministerio de Educación (Mineduc) en su página oficial de Internet:

\begin{abstract}
Basándonos en los datos presentados por fuentes del Mideplan [encuesta Casen 2000], podemos afirmar que la pobreza, dada en mayor medida en la población indígena, conjugada con factores tales como la descontextualización de los aprendizajes en relación a la cultura y la lengua local, inciden directamente en los bajos niveles de desempeño, observados en los resultados de la prueba SIMCE, de aquellos establecimientos educacionales que cuentan con niños y niñas indígenas entre sus alumnos (Mineduc 2005).
\end{abstract}

Un año antes, el Programa de EIB del Mineduc ya había explicitado la necesidad de implementar "diversas estrategias que tienen como finalidad la contextualización del currículum a la cultura y a la lengua indígena" con el fin de abordar su principal problemática: "los bajos logros de aprendizajes de las escuelas focalizadas" (Mineduc 2004:1).

En pro de estos esfuerzos el Estado ha ido generando prácticas discursivas, acciones y manifestaciones que tienden a crear las condiciones y configurar los modos de hacer EIB y que, siguiendo una perspectiva foucaultiana, analizamos como un tipo de dispositivo que, primero, se articula a nivel de discurso en lineamientos institucionales, prescripciones curriculares y en la elaboración en serie de los proyectos educativos institucionales de las escuelas con EIB; segundo, da lugar a acciones como los llamados a concurso para postular proyectos y la ejecución de rituales y representaciones institucionales y, tercero, se manifiesta en concreciones materiales como las modernas edificaciones escolares. El dispositivo es en esta perspectiva una "red de relaciones" que permite vincular funcionalmente discursos, acciones y concreciones que, a pesar de su aparente heterogeneidad, cumplen una misma función estratégica definida por su génesis, esto es, su objetivo estratégico originario. Una vez puestos en circulación los mecanismos del dispositivo, se genera una sobredeterminación funcional, esto es que "cada efecto positivo o negativo, querido o no-querido, entra en resonancia o contradicción con los otros y exige un reajuste" (Castro 2004:99). En tanto intervención externa, el dispositivo de la educación intercultural genera en las comunidades indígenas acciones y respuestas que pueden ser leídas como formas de resistencia para la reapropiación de espacios y discursos que tienen su legitimación en procesos históricos de interpelación de la dirigencia mapuche-huilliche al Estado y sus instituciones.

Es en este espacio de instalación de la EIB donde se sitúan nuestros análisis, en el territorio mapuche-huilliche conocido como Fütawillimapu ${ }^{2}$, con particulares características de identidad territorial, que incluyen su variedad dialectal, su religiosidad y especialmente sus organizaciones tradicionales y modernas. Por una parte, desde la tradición se mantienen los cacicados, organizados según jurisdicciones que responden a la Junta General de Caciques (que reconoce su fundación en el año 1793 con la firma del Tratado de Paz de Las Canoas), y la antigua organización en comunidades, algunas de éstas, en el área más nortina del territorio, agrupadas en Consejos de Lonkos, que hoy dialogan con el cacicado aun cuando no se encuentran bajo su jurisdicción. Por otra parte, líderes no tradicionales han surgido de las asociaciones y comunidades indígenas -como presidentes, secretarios, etc. de estas organizaciones- a partir de la dictación de la Ley $19.253^{3}$ (Ministerio de Planificación y Cooperación 1993).

Una observación atenta de estos contextos y sus discursos revela resistencias y tensiones en lo 
escolar y más evidentemente en lo comunitario. Esto resulta, sin embargo, marginal para las políticas educativas del sistema: el currículum oficial para la interculturalidad asume el principio de neutralidad sociopolítica que caracteriza al sistema educativo general y permanece constreñido al objetivo central estatal de mejorar los aprendizajes de los alumnos $^{4}$. Sobre esta base se privilegian en la escuela intercultural sólo aquellos aspectos de la cultura indígena y local que sean funcionales y pertinentes para el desarrollo de los contenidos disciplinarios. Las políticas educativas generan así una lógica de invisibilización y cierre frente a los procesos sociales que movilizan lo local, espacio en el que sin embargo se desarrolla una dinámica propia en lo cultural, social y organizacional caracterizada hoy día por una creciente conciencia y voluntad de la dirigencia indígena para construir y transitar procesos de recuperación de la memoria colectiva y reelaborar nuevas connotaciones y sentidos desde la subalteridad. En palabras de Manoel Castelo Branco (Salas 2005:29), percibimos un contexto de "realidad humana en situación de opresión social" y, muy especialmente, una situación de "negación del ser".

Es en estos espacios conflictuados -entre el centro y lo local, entre la modernidad y la tradición- en los que la educación intercultural bilingüe se inserta direccionada desde el Estado, a partir de políticas sustentadas en la Ley Indígena. La EIB como "espacio del Estado" gerencia desde sus inicios los recursos como Programa y, el modus operandi va por la vía de proyectos que determinan los modos de hacer interculturalidad en la escuela. Con la instalación "desde arriba" se ordenan también los discursos de educación intercultural que ingresan a las escuelas. Docentes de diferentes establecimientos replican sin mayor cuestionamiento el discurso estatal -Ley Indígena y más tarde lineamientos del Ministerio de Educación- que justifica la incorporación de escuelas al programa por factores numéricos de densidad poblacional indígena. En esta focalización, el contexto comunitario emerge como una carga para la escuela, y los objetivos remediales -para mejorar ("subir") la autoestima de los niños y sus aprendizajes- son asumidos con la mejor intención para abordar eficientemente este problema que entorpece el logro de más altos estándares educativos.

De este modo, la EIB de raigambre ministerial se instala direccionada por decisiones translocales, incorporando enunciados cuya autoría funciona como principio de agrupación del discurso, como unidad y origen de sus significaciones y como foco de su coherencia ${ }^{5}$, en una serie de escuelas que incluyen tanto establecimientos municipales como particulares subvencionados. Ambos tipos de establecimientos están incluidos en esta aproximación a los modos de construir la educación intercultural.

\section{Edificio Escolar e Institución Encarnada}

Nos interesa en este punto abordar la escuela en su materialidad concreta, como manifestación que representa y da continuidad al centro, como reajuste visible y constante del dispositivo de una modernidad en la que se estructura y reacomoda la educación intercultural.

Las recientes políticas estatales de educación han enfatizado el mejoramiento y reposición de la infraestructura arquitectónica escolar, ello porque las escuelas -y especialmente las ubicadas en zonas rurales- venían evidenciando un deterioro que hacía absolutamente inadecuados los espacios de enseñanza, lo que no desestima otro factor no menos importante en la lógica de la gestión eficiente: la visibilidad a corto plazo de cambios como los que generan las nuevas edificaciones, en oposición a los efectos de largo plazo que se producen a través de las reformas curriculares.

Esta política se ha aplicado en el medio rural especialmente a establecimientos educacionales de dependencia municipal, dando como resultado la aparición de modelos de edificación escolar de tipo urbano, discontinuos respecto del paisaje rural, con estructuras de cemento y hormigón y dimensiones comparativamente monumentales, algunos con dos o tres pisos de altura, con canchas y estacionamientos totalmente pavimentados. Por otra parte, las escuelas particulares subvencionadas ${ }^{6}$, no cubiertas por los programas de infraestructura, mantienen las formas arquitectónicas propias de la construcción tradicional en madera, de un solo piso, de base rectangular, con un corredor techado abierto al patio. Su crecimiento es por ampliaciones de similar diseño y responde a necesidades inmediatas.

Una primera mirada nos permite anticipar que ambos tipos de edificación se relacionan de forma distinta con el paisaje rural, con las personas que interactúan en sus espacios internos y circundantes, a la vez que albergan modos diversos de construir EIB. Sería ingenuo postular que el edificio mismo 
determina el modo de construir la interculturalidad, que una práctica docente no puede liberarse y reconvertir altura, distancia y materia para forjar una construcción pedagógica alternativa. Sin embargo, la materialidad del edificio actúa como concreción simbólica que hace parte del dispositivo en el que confluyen las dependencias administrativas y curriculares, y que exhibe el carácter de las relaciones entre la sociedad civil y el Estado, donde este último enmarca y diseña, intelectual y materialmente desde afuera, los modos en que la escuela asume las relaciones entre identidades y diferencias. Es la "institución encarnada" cuyo "tiempo cronológico escolar que rige "los momentos de entrada y salida, la duración de las clases y los recreos, etc." y cuyo "espacio físico escolar, que establece los límites del adentro y el afuera (calle/escuela, aula/patio), la disposición del mobiliario, los desplazamientos de los sujetos, etc." son "dimensiones regladas" que forman parte del "control burocrático-administrativo" estatal (Milstein y Mendes 1999:38).

\section{La Modificación del Paisaje Rural}

La instalación de la nueva y moderna edificación escolar municipal que emerge sobre amplias áreas de cemento, comparte identidad con otros elementos propios de la modernidad y la civis, tales como los grandes puentes y las nuevas carreteras que intervienen el paisaje rural. Como elemento común a ellas, el cemento pasa a formar parte de una red de significaciones históricamente construida como violencia simbólica. La civilización avanza en el medio rural a través de sólidas vías, de puentes que se instalan como hitos del futuro desarrollo vial que se va apoderando del paisaje natural y de las nuevas escuelas de estilo citadino. La modernidad se instala atrayente y rechazada a la vez.

Atrayente porque la mejora vial beneficia el transporte hacia la ciudad y sus servicios, rechazada porque con los cambios de la modernidad llegan las empresas forestales e hidroeléctricas que invaden territorios y explotan el medioambiente, desmejorándolo, en beneficio de grandes capitales externos. En este espacio, la instalación de modernas edificaciones entra en el juego de la modernidad, que -siguiendo a Escobar (2002)- se caracteriza por la generación exógena de normas, las que serían "producidas por mecanismos expertos, impersonales, que parten del conocimiento experto en relación con el Estado"; y por la permanente descontextualización, esto es, por el "arrancar la vida local de su contexto". Como parte también de esta modernidad, el optimismo pedagógico - una de las corrientes de las teorías del consenso- estima, según Gvirtz et al. (2007:70-75), que la superación de niveles educativos y la consecución de títulos promueven el ascenso y la obtención de mejores salarios, lo que en consecuencia permitiría explicar los resultados micro y macro del sistema económico a partir de la variable educación. El optimismo pedagógico es asimismo consustancial al optimismo tecnocrático que condiciona el desarrollo al dominio de un saber técnico supuestamente neutro y cuyas políticas intervienen la realidad desde criterios externos, pretendiendo obtener resultados mediante una suerte de consigna, según la cual, frente a cada problema o necesidad, la respuesta es un proyecto o una licitación. El optimismo tecnocrático parece resultar menos eficiente mientras mayor distancia hay entre el nivel de toma de decisiones y el nivel de base de intervención, como sucede especialmente en las políticas que se aplican a la realidad indígena.

La modernidad y su instalación en el paisaje rural, el optimismo pedagógico y el optimismo tecnocrático se muestran en su reverso en esta historia que aquí consignamos, narrada por un intelectual mapuche-huilliche, donde la ironía desplegada, los saltos de lo global a lo particular y las descripciones desde el margen dan cuenta de una sofisticada mirada crítica desde lo local:

\section{Hoy día en Chile la brecha digital no} existe: "Ricardo Lagos cuando asumió la Presidencia de la República se comprometió a crecer con igualdad y en uno de sus discursos -que lanzó el 21 de mayo del 2000-dijo que invitaba a todos los pueblos de Chile a ingresar a la era digital y por lo tanto en Chile todos van a ser alfabetizados digitalmente y ese fue un discurso que pronunció antes de que caigan las Torres Gemelas, allá en el World Trade Center y ahí hay una foto que se sacó con Bill Gates, donde le regalaron cinco computadores satelitales para todos [cada uno de] los municipios del país. En Lago Ranco hay una biblioteca, con Internet satelital y esa fue una primera acción, esa fue una donación que hizo Bill Gates. Pero también Bill Gates le obsequió dos camiones que venían equipados con toda la tecnología para alfabetizar a todos 
los ciudadanos de este país que no estén en escuelas, para el campesino, para los dirigentes de juntas de vecinos, para las comunidades indígenas.

Y el camión estaba a pasar dos días por comuna y los tenían de cinco horas de clases por grupo, entraban como veinte, veinticinco personas en el camión. Tenía todas las comodidades, por ejemplo aire acondicionado, todas las comodidades que necesitan... equipado completo... y ahí las personas se iban a inscribir voluntariamente, iban pasando y estaban más o menos cuatro horas. Después ya se les invitaba a un almuerzo y se iban para sus casas... entraba el otro grupo. $\mathrm{Y}$ en dos días debían haber pasado más menos unas doscientas personas. Entonces, [cuando] llega el camión a Lago Ranco, aparece como una nave espacial y se abre la cuestión!... y la gente lo ve y todos nos asustamos, los camiones eran grandes... igrandes! pero equipados, modernos, con escaleras, tenían compuertas, todo digitalizado, paraban y se abría la cuestión, tú podías entrar, igual que [a] una sala de clases. Yo fui a verlo igual, porque era una cuestión moderna, compleja, única... jamás vista. Entonces la gente que entraba adentro se ponía nerviosa, transpiraba y... lo primero que tenía que aprender era a manejar el ratón y ahí no... no podían porque ellos movían la cuestión... ise iba para todos lados! El ratón era con luz, alumbraba... y las pantallas eran delgaditas... Al otro día tenían que volver a.... a practicar lo que aprendieron el día antes, entonces, primero era prender el equipo y después apagarlo, entonces la gente no aprendió a apagar el equipo, no aprendió a prenderlo, ni mucho menos a manejar el ratón, porque nunca lo pudieron tomar bien, lo apretaban demás fuerte o bien le tenían miedo.... todo el sistema de nerviosismo que al final pasaba la hora, pasaba la hora, y tenían que venir los otros grupos, y al final que nadie [aprendió]... lo único que queda en la mente de la gente es que Lagos envió un camión y que entramos a mover el ratón, eso es todo. Y hoy día en Chile la brecha digital no existe: ¡todos tienen su certificado!, a todos les entregaron certificado, todos tienen su certificado de que están alfabetizados digitalmente. Y el camión recorrió... eran dos camiones, recorrió desde Arica a Punta Arenas, venían desde el norte, pero, unos camiones equipados completos y como con veinticinco computadores, estuvo en San Pablo, estuvo en Quilacahuin. En San Juan de la Costa, ahí fue peor todavía, ahí fue peor la desgracia, porque ahí fueron los profesores, todos los que estaban en el círculo de La Misión... los peñis [sólo] vieron de lejos el camión. Al menos, los indios de Lago Ranco alcanzaron a mover el ratón, porque el Alcalde no permitió que ningún funcionario municipal, ni de la salud, ni nadie, solamente la gente de base fuera. $\mathrm{Al}$ menos en eso Ranco fue beneficiado, porque los pobres, los indios, movieron el ratón... ¡los de San Juan ni siquiera eso! ¡Esa gente ni siquiera tuvo la posibilidad de mover el ratón!, y en Quilacahuin pasó lo mismo, todos fueron a los camiones, los funcionarios, todos esos que trabajan ahí en la Misión de Quilacahuin, todos esos fueron a mover el ratón, pero el resto ... ni eso. ¡Y muchos ni siquiera se dieron cuenta de que pasó el camión de Lagos! (Dirigente 3, entrevista personal 2008).

La frase que hemos seleccionado de título ilustra la ironía con que el narrador relata la historia. Esta proviene del hecho que la brecha -pese a la certificación- no sólo sigue ahí, sino que paradojalmente se vuelve más visible con la visita de los camiones. En el asombro que provoca esta especie de espectáculo y en la imposición de unos tiempos absurdamente rápidos -como ocurre en los viajes turísticos-que permiten a los ciudadanos no escolarizados apenas asomarse y rozar esta visión extraordinaria, lo único que alcanza a quedar en sus mentes "es que Lagos envió un camión y que entramos a mover el ratón, eso es todo". El relato pone de manifiesto la realidad reprimida y el intento de ocultarla, transmutarla más bien, a través de la certificación -mecanismo que remite al optimismo pedagógico-, y evidencia el abismo que separa la realidad de "los pobres, los indios" de la vida moderna y su tecnología ${ }^{7}$. En otra narración -cuya modalidad de enunciación también privilegia la ironía- la escuela y el silabario representan de un modo semejante el encuentro 
de mapuches con la modernidad: los ancianos que antiguamente "pasaron" por la escuela vislumbraron que el silabario era fuente de saber, representación máxima de la escolarización, aunque muchos de ellos nunca aprendieron a leer pese a repetir varias veces el primer año.

Vemos aquí escenificaciones del avance de la modernidad en espacios socioculturales concretos, instalaciones cuya interpretación bordea lo mítico. Sin embargo, los resultados de estos encuentros pueden ser disímiles. Al respecto, Escobar (2002) enfatiza que "el mundo actual se compone de variaciones múltiples de la modernidad, resultantes de la infinidad de encuentros entre la modernidad y las tradiciones. De ahora en adelante (y desde antes), nos vemos abocados a la existencia de modernidades 'híbridas', 'locales', 'mutantes', 'alternativas' o 'múltiples'". En el espacio rural, las modificaciones constituyen espacios de frontera entre la modernidad y las tradiciones y en esta interacción, como señala Escobar (2002), ocurre que "cada acción de desarrollo es potencialmente un acto de contradesarrollo (...) Cada acto de contradesarrollo es potencialmente la semilla de una modernidad alternativa". En este sentido, el contradesarrollo estaría basado en la práctica cotidiana, en la que todo desarrollo exógeno es apropiado por la gente, por la comunidad y reorientado a acciones que sustentan una racionalidad distinta, que apunta a posibilidades alternativas de desarrollo. En el siguiente punto, abordamos este problema en los contextos en estudio.

\section{Las Reacciones del Contradesarrollo}

En gran parte la resistencia a la modernidad en las comunidades mapuche-huilliches ocurre fuera de la escuela, generalmente de manera subrepticia, pero a veces se manifiesta también en espacios que la misma modernidad ha instalado, como ocurre en el reverso de la señalética que bordea el camino recién pavimentado entre Bocatoma y Panguipulli, donde se inscriben protestas contra la instalación de hidroeléctricas, la misma queja que ha sido reiterada por la dirigencia mapuche al constatar año a año el avance sobre sus tierras del agua de la represa. Problemas como éste han impulsado a las comunidades a reorganizarse. El dirigente que nos habló de su preocupación por el crecimiento del lago artificial, ha trabajado activamente durante 10 años -como él mismo señala- para formar el Consejo de Lonkos, organización que espera pueda interlocutar con diferentes autoridades. Actualmente se han incorporado siete comunidades pero esperan ampliar la organización por lo menos a 20 comunidades, porque "somos amplios para trabajar" y porque "los que podemos hablar, hablamos y los que no hablan, están sufriendo". Pocos han despertado, dice el Lonko, y en su reflexión, de alguna forma homologa el avance invasivo del lago artificial, con la injusticia y el abuso de las instituciones oficiales, en un juego de poderes en el que las personas mapuche tampoco logran perfilar bien sus reales demandas indemnizatorias:

es lamentable la situación de nuestra raza que no se le reconoce. Así estamos, haciendo llegar - por lo menos por los caminos- ya hicimos llegar al gobierno con funcionarios que vengan a ver a terreno que no estamos inventando cosas. Son cosas hechas, como ese lago de tanta superficie. Cuando en aquellos años se tomó [los terrenos] la empresa y después se empezó a llenar el lago, cuando trancaron ahí, le taparon las quintas a algunos y a otros hasta la casa llegó. ¿Qué fueron a reclamar? Ellos fueron a reclamar sus manzanas que estaban flotando en el lago y no fueron a reclamar el árbol ni la tierra. Allá les dijeron “¿cuántos sacos perdió?, evalúe los sacos de manzana y firme aquí y está pagado el costo". No ve que el abuso grande sigue con nosotros (Lonko 1, entrevista personal 2007).

En este relato el Lonko manifiesta la desconfianza de la dirigencia por los avances del desarrollo y sus limitadas reparaciones. Conscientes de ello, reclaman una educación propia y vinculan ésta con la posibilidad de elaborar una política propia de desarrollo. En esta misma línea, dice una dirigente:

[la educación, la lengua mapuche] tiene que llegar a ser importante en nuestra política de desarrollo como pueblo, no sólo como pueblo sino como sociedad hoy día dominada" también dice soñar con que "nuestro idioma nos sirva por ejemplo para generar una nueva tecnología, que nos sirva como para generar una nueva estrategia de desarrollo, que nos sirva hoy día por ejemplo para rellenar de conocimiento y 
contenido lo que es el agro, el etnoturismo

(Dirigente 1 entrevista personal 2007).

Sin embargo, no toda la dirigencia tiene las mismas preocupaciones. En sectores que sustentan una visión política hay reclamos respecto de cómo actualmente se encuentran divididos por la emergencia -a partir de la Ley Indígena- de un nuevo tipo de liderazgo. Como lo expresa un Inalonko ${ }^{8}$ "hoy día se ven en realidad dos tipos de dirigentes, un dirigente que ha trabajado en defensa de los derechos territoriales -en este caso, en la Región del Fütawillimapu, son los cacicados- y los otros dirigentes que hoy día están formados a través de la personalidad jurídica de la Ley Indígena que está actualmente vigente". El mismo dirigente señala que mientras nosotros "estamos trabajando para la autonomía del pueblo mapuche", los otros que emergen de la Ley Indígena "se duermen. ¿por qué se duermen? Porque están interesados en sacar un proyectito, si el proyecto más bien hoy día, es más bien un acto de genocidio, yo diría. Porque ¿qué se saca? Que estemos durmiendo con un Programa Orígenes" (Dirigente 2, entrevista personal 2007). La reorganización de la dirigencia mapuche, en sectores de reconocida tradición étnica -como Bocatoma, en la Región de Los Ríos y San Juan de La Costa, en la de Los Lagos-, y la emergencia de respuestas contra-hegemónicas, aporta las condiciones para el reclamo de una EIB más propia, una EIB menos exógena, "aséptica" o "pasteurizada" y más comprometida con los intereses y necesidades de las comunidades. Los dirigentes expresan así su reclamo contra políticas que tienden a neutralizar su capacidad de interlocutar como colectivo y visualizan, en cambio, en la educación endógena una posibilidad de formación de sujetos que colaboren en potenciar un desarrollo propio.

\section{La Escuela con EIB Pasteurizada}

En la instalación del proyecto de la interculturalidad hay, sin embargo, algunas escuelas que no permanecen indiferentes ante los problemas de la comunidad y los dirigentes reconocen en ellas una apertura a los temas que ellos plantean, especialmente cuando en algunas escuelas, como la de Bocatoma, les ha sido posible hablar sobre ello en alguna reunión o acto y más aún, cuando escuelas como la de Trosco (San Juan de La Costa) invitan a autoridades winkas y mapuches a parlamentar sobre sus problemas. Pero, en general, la percepción que prevalece es la de una escuela ajena, que pese a estar inserta en el propio territorio mapuche, transmite un currículum exógeno y que, cuando incorpora elementos mapuche, los neutraliza, los integra "pasteurizados", despojados de su sentido original y de toda mención o posicionamiento frente a relaciones asimétricas de poder. Esta situación es resentida por líderes más políticos y llega a generar controversia entre éstos y presidentes de comunidades, cuyo cargo surge precisamente a propósito de la Ley Indígena.

Una carta a una autoridad educativa regional (Secretario Regional Ministerial) firmada por varios dirigentes pide cambios más sustantivos, según los cuales las escuelas de comunidades mapuches deben tener profesores mapuches, o bien, estar en manos de Lonkos y es que no se confía en que la escuela con EIB situada en un locus de enunciación ajeno canalice verdaderamente intereses mapuches. Así lo expresa un joven de la comunidad que ha egresado hace no mucho tiempo de una de estas escuelas, cuando dice: "yo creo que el colegio difunde la historia que les pertenece a ellos y nunca van a contar la historia de lo que sucedió con mi pueblo" (Comunero 1, entrevista personal 2007).

La comunidad reclama la historicidad del currículum, "la verdadera historia de los acontecimientos que sucedieron tiempo atrás", pues para algunos sectores de la dirigencia, la incorporación de contenidos culturales de la tradición mapuche en la escuela se torna objeto de sospecha. La celebración del wetripantu en la escuela es percibida como posible representación para mantener una imagen y no como "cosas que son de la propia gente". Este tipo de percepciones dirigenciales mapuche pueden encontrar una clave de sustentación en Walsh (2002), quien concentra los planteamientos de diversos autores en una mirada crítica de la globalización de los mercados y sus concomitancias sociales y culturales:

Zizek (1997), entre otros, sostiene que en el capitalismo global de la actualidad opera una lógica multicultural que incorpora la diferencia mientras que la neutraliza y la vacía de su significado efectivo. En este sentido, el reconocimiento y el respeto a la diversidad cultural se convierte en un componente central del capitalismo global, o en lo que Quijano (1999:101) denomina 
"su otra cara", el nuevo modelo de la dominación cultural posmoderna (Jameson 1996) que ofusca y mantiene a la vez la diferencia colonial a través de la retórica discursiva del multiculturalismo y su herramienta conceptual de la interculturalidad entendida de manera integracionista, esta interculturalidad no apunta a la creación de sociedades más igualitarias sino, más bien, al control del conflicto social y la conservación de la estabilidad social, con el fin de impulsar los imperativos económicos del modelo de acumulación capitalista (Walsh 2002).

En Walsh se lee la estrategia del modelo de educación intercultural estatal chileno. De hecho, a pesar de la implementación de la educación intercultural en las escuelas, la dirigencia mapuche sigue percibiéndose en contradicción con el Estado, del que reclama la promesa incumplida del reconocimiento constitucional de los pueblos indígenas, que les permitiría avanzar en un desarrollo endógeno porque -como dice una dirigente huilliche- "no queremos que nos impongan un desarrollo, que ellos piensen lo que para nosotros es bueno". La misma dirigente enfatiza en temas que considera primordiales: "quiero hablar igual de un tema, de la integración, de cómo el Estado chileno nos quiere integrar a la educación de ellos, nos quiere hacer olvidar todo lo que nosotros somos" (Dirigente 1, entrevista personal 2007). En este sentido, es relevante descubrir que la dirigencia visualice el carácter culturalista y ahistórico 9 del modelo curricular institucional, ya que esta visión dirigencial se ve ratificada en los documentos ministeriales -programa de EIB del Mineduc-que explicitan la instrumentalización de la cultura indígena y local, vía contextualización curricular, para el logro de aprendizajes del currículum nacional. Esto desperfila a la EIB, en tanto la sitúa (y evalúa) como una más de las iniciativas compensatorias del Estado.

Por ello, el discurso del Ministerio y el de la dirigencia mapuche de raigambre más política son dos discursos que no se encuentran. Mientras el primero es técnico y aparentemente neutro, el de los dirigentes mapuches es un discurso políticamente situado y explicitado. Sus preocupaciones van por la no integración, por la necesidad de contar con profesores mapuches, de incorporar contenidos propios, pero enfatizan especialmente respecto de contenidos que evidencien la situación de desmedro social en que viven. Aun así, hay algunas escuelas que logran incluir ambos discursos -el ministerial y el de la dirigencia- en una suerte de acomodación que permite que el uno y el otro se intercepten lo menos posible en el currículum escolar. Sus docentes y directivos son mapuches comprometidos en una educación transformadora, a la que denominan educación mapuche en oposición a la educación intercultural (Alvarez-Santullano et al. 2007) y reconocen que a la vez deben preocuparse por hacer lo que el Ministerio pide, ya que de todas formas hay que rendir cuentas del logro de los aprendizajes del currículum oficial a través del sistema de medición de la calidad de la enseñanza (SIMCE).

Sin embargo, en la mayor parte de las escuelas, la inclusión de contenidos mapuches no se roza con las solicitudes dirigenciales y la educación intercultural sigue siendo allí un acomodo de la educación nacional para responder de manera más eficiente a sus propios objetivos. Entonces nos preguntamos ¿cómo resuelve la escuela estos mandatos?, ¿dónde y a quién muestra la escuela con EIB sus logros en materias de educación mapuche?

\section{La Escuela Muestra su Diámetro}

La escuela, y particularmente la escuela municipal, como hemos visto antes, no sólo replica los códigos arquitecturales de la modernidad, sino que además opera como vehículo de políticas públicas. El nuevo emplazamiento arquitectónico traslada la urbanización al espacio rural y la edificación deviene en performance que instala e impone un nuevo ordenamiento de las relaciones sociales. En este espacio, la escuela y sus diversos actores elaboran representaciones sobre la vida escolar, a través de prácticas y rituales que la sociedad tradicionalmente le ha impuesto como institución. Esta representación sobre sí misma se actualiza en actos públicos mediante los cuales la escuela enmarca, consciente o inconscientemente, sus directrices con la comunidad. Allí, los participantes asumen diversos roles, unos hablan en el pódium, otros representan y luego hay otros a quienes se dirige la representación. Los actos públicos son preparados detalladamente, en lo posible sin dejar nada al azar. Prevalece la planificación y artificialidad por sobre la cotidianeidad, y se activan símbolos que ordenan la recepción y ubicación jerárquica de los actores sociales. El acceso al pódium y el uso de micrófonos 
establecen espacios de jerarquización del habla y de la representación misma. El auditorio se ordena: delante se sitúan las autoridades institucionales que representan al Estado, a veces también autoridades mapuches en una escenificación que puede otorgarles acceso al habla -se las suele convocar de manera casual para decir "unas palabras" o para "dar un saludo" que el contexto mismo, cargado de emotividad compensatoria, obliga al discurso laudatorio- y, luego, la escuela que se representa revestida de armónica tolerancia mediante la escenificación de cuadros rituales mapuches aplaudidos por todos los presentes. La puesta en escena de los rituales y fiestas surge como fotografía, como un pedazo recortado y discontinuo de historia. El edificio de cemento favorece la escenificación de un wetripantu ${ }^{10}$ con la ñuke mapu ${ }^{11}$ cubierta de baldosas. Entre el $e f k u^{12}$ y la ñuke mapu se interpone el cemento de la escuela.

Este edificio escolar genera formas de espectáculo exterior que suelen ser admiradas y resentidas por quienes sólo tienen derecho a transitar por este espacio que bien cabe en los no-lugares de Augé (2004). Un Lonko lo expresa así:

Me duele el alma de ver nuestra raza discriminada y sufriendo por muchas cosas, me duele el alma de ver un niño a pata caminando cinco kilómetros para educarse, me duele de ver una madre que no tiene esposo, haciendo de mamá y papá, caminando con su negocio de canastos de distintas verduras para ganarse y educar a su hijo. Eso me duele. ¿Qué pasa con las autoridades?, les gusta llegar al lado del camino, no les gusta caminar cinco kilómetros para adentro (Lonko 1, entrevista personal 2007).

En la otra orilla, la escuela mapuche con arquitectura de escuela de campo utiliza sus salas para reuniones con lonkos y en el patio, entrada ya la noche, circulan las bandas para dirigirse a celebrar el wetripantu en un espacio consagrado para ello y ubicado al costado de la misma escuela. Incluso una ceremonia muy occidental, como la graduación de alumnos de $8^{\circ}$ año, se realiza al modo mapuche. Los alumnos que se licencian son recibidos como miembros de la comunidad ritual mediante un efku en el que participan activamente ellos, sus padres y la comunidad y en el que se hacen invocaciones para que los niños tengan la fuerza (newen) necesaria para enfrentar su vida de mapuches en una sociedad que no los favorece. Nadie observa aquí a los actores, nadie los aplaude, no hay tolerancia externa, el ritual es propio y no representación para otros.

Dice Augé (1998:156) de París que aleja a quienes pueden trabajar en la ciudad pero no vivir en ella. Agregamos que, del mismo modo, hay escuelas que se vuelven propias y hay otras que junto con recibir, distancian. Hay espacios escolares que favorecen al sujeto en su recreación histórica y otros que clausuran esta posibilidad. Palamidessi (2001) describe este currículum moderno de la siguiente manera:

Desplazamiento y escisión fundamental que destruye lo local en función del espacio nacional; puesta en circulación de normas modernas y pautas públicas; constitución de un espacio en que estos saberes serán homogeneizados, compartimentalizados, emplazados y administrados. La construcción de este primer currículum moderno para la escuela elemental sobre la base de espacios cerrados, discontinuos, de emplazamiento fijo, implicó la construcción de un medio "artificial" que excluía los intercambios, segmentaba las comunicaciones, separaba el medio escolar de la vida social. Hasta cierto momento los planes de estudio y los horarios enunciaron una distribución de ocupaciones en función de una división de duraciones en segmentos detallados, sucesivos y paralelos. De allí la disposición de los programas a presentar un stock ordenado de objetos, lecciones y ejercicios para administrar, distribuir el tiempo y las ocupaciones. En función del buen orden de la maquinaria escolar (Varela y Álvarez Uría, 1991) los objetos de enseñanza y las ocupaciones fueron homogeneizados, clasificados, cuantificados (Palamidessi 2001:30).

Creemos que estos edificios de moderna instalación textualizan, construyen una narración del modo en que los sujetos se educan. Pensamos en la necesidad de preguntarnos sobre la representación que construyen los docentes y los alumnos sobre sí mismos en una escuela que se construye sólida y monumental, que privilegia mostrar su diámetro hacia 
afuera y que está arquitecturizada desde el cemento, el control, la jerarquía, la modernidad y las culturas urbanas. La respuesta probablemente se relaciona con la reproducción de relaciones asimétricas, con soluciones pedagógicas que se elaboran y legitiman desde la hegemonía, donde el Estado-metrópoli se impone sobre lo local y -seguimos a Palamidessi de nuevo- donde el sujeto cognitivo o epistémico -el ideal normativo de esta psicología- es postulado como un sujeto universal.

La nueva arquitectura de la escuela resalta como espacio narrativo donde el Estado de la modernidad se construye ideológica y materialmente. Los amplios estacionamientos pavimentados de algunas de ellas evidentemente no son para los campesinos que transitan a pie, a caballo, en carreta o en micro, sino para los funcionarios que asisten a los actos públicos. $\mathrm{La}$ sala de espera se yergue en el espacio de dominio de la administración, membrana que filtra quiénes son recibidos y quién recibe, así como el tiempo de espera. Los nuevos espacios intermedios, pasillo de ingreso, oficina de espera -para hablar con el Director o los profesores-dan lugar a una nueva o al menos mayor jerarquización. La distribución del edificio conlleva nuevos roles que deben cumplir nuevos funcionarios, se activan nuevos protocolos al interior de la escuela y en el acercamiento-distanciamiento entre escuela y comunidad. La escuela se yergue encementada y aséptica, desligada del problema político, para no ser perturbada en su tarea de conseguir los rendimientos que el Estado requiere generar.

En este recorrido que partió por las edificaciones, hemos tratado de respondernos ¿cómo se construye la educación intercultural detrás de los muros de cemento de estas edificaciones que reemplazaron a las escuelas de madera? ¿Cómo se corporiza el currículum de la diferencia en el tránsito por los patios de cemento, en la sala de espera que permite atisbar apenas el complejo circuito de pasillos que desemboca en múltiples salas? ¿Cómo se despliega y amolda la "pertinencia educativa" de la propuesta intercultural del Ministerio de Educación en la sólida estructura del edificio que la contiene?

El currículum de escuelas con EIB -hasta ahora al menos- se construye con contenidos fragmentados, dispersos en subsectores de aprendizaje, discontinuos en su tratamiento temporal. Los saberes mapuches, su selección, uso y formas de inserción en el currículum dependen de la voluntad del docente, pero aun cuando éste tenga la mejor de las voluntades, los contenidos mapuches aparecen subordinados a los contenidos oficiales. Nombres de animales en lengua mapuche, partes del cuerpo humano, rellenan estos espacios del aula en la medida en que los contenidos disciplinarios y las habilidades y competencias universales requieran de contextualización para sus mejores logros.

Mientras, en la otra escuela, más mapuche, cercana al contradesarrollo, el sentido del colectivo mapuche, la necesidad de deshacer y rehacer la historia intenta recontextualizar la modernidad, apropiarse de los espacios y construir identidades y discursos alternativos.

Agradecimientos: A CONICYT por financiar esta investigación vía Proyecto Fondecyt 1050634 (2005-2007) y a los evaluadores, cuyas sugerencias nos permitieron mejorar el texto.

\section{Referencias Citadas}

Alvarez-Santullano, P., A. Forno y R. Rivera

2007 La educación intercultural en el discurso directivo docente mapuche: posicionamiento desde los márgenes. En Patrimonio Cultural Mapunche. Derechos Culturales y Patrimonio Mapunche Volumen II, editado por T. Durán, D. Catriquir y A. Hernández, pp. 283-295. UC TEMUCO, Temuco.

Augé, $\mathrm{M}$.

1998 Hacia una Antropología de los Mundos Contemporáneos. Segunda edición, Gedisa, Barcelona.

2004 Los No Lugares. Espacios del Anonimato. Una Antropología de la Sobremodernidad. Gedisa, Barcelona. Balart, C. e I. Césped

s/f Monografía Temática: Mitos y Palabra Creadora del Mundo en la Literatura Hispanoamericana http://www.umce. cl/ cipumce/publicaciones/cuadernos/facultad_de_historia/ monografias_tematicas/cuaderno_15/mitos_palabra_creadora_invencion.htm (5 enero 2008).

Berman, $\mathrm{M}$.

2000 Todo lo Sólido se Desvanece en el Aire. La Experiencia de la Modernidad. Siglo Veintiuno, México.

Castro, E.

2004 El vocabulario de Michel Foucault. Un Recorrido Alfabético por sus Temas, Conceptos y Autores. Universidad Nacional de Quilmes, Buenos Aires.

Cox, C., editor

2005 Políticas Educacionales en el Cambio de Siglo. La Reforma del Sistema Escolar de Chile. Segunda edición, Editorial Universitaria, Santiago.

Diario Austral de Valdivia

2004 Pueblo Mapuche celebra el Wetripantu. (20 junio) http://www.australvaldivia.cl/site/edic/20040619234617/ pags/20040619235325.html (5 enero 2008). 
Escobar, A.

2002 Globalización, desarrollo y modernidad. (s/f). http:// www.oei.es/salactsi/escobar.htm (5 enero 2008).

Foucault, M.

1992 El Orden del Discurso. Tusquets, Buenos Aires.

Gvirtz, S., S. Grinberg y V. Abregú

2007 La Educación Ayer, Hoy y Mañana. El ABC de la Pedagogía. Aique Grupo Editor S.A., Buenos Aires.

Milstein, D. y H. Mendes

1999 La Escuela en el Cuerpo. Miño y Dávila, Buenos Aires.

Ministerio de Educación, Chile

2004 Orientaciones para la Planificación Regional del Programa de Educación Intercultural Bilingüe. (s/f). http://www.mineduc.cl/biblio/documento/200708241047270.programa. doc (7 enero 2008).

2005 Programa EIB/Orígenes. Problema y Justificación. (s/f). http://www.mineduc.cl/index3.php?id_portal $=28 \& i d$ seccion $=2145 \& i d \_c o n t e n i d o=6027$ (7 enero 2008).
Ministerio de Planificación y Cooperación de Chile

Ley 19.253 establece normas sobre protección, fomento y desarrollo de los indígenas, y crea la Corporación Nacional de Desarrollo Indígena. (s/f). http://www.politicaspublicas. cl/leyes/Ley_19253.htm (7 enero 2008).

Moreira, A.

1997 Currículo: Questões Atuais. Papirus, Campinas-SP.

Palamidessi, M.

2001 Un nuevo régimen de verdad y normalización: el (largo) reordenamiento del currículum para la escuela elemental. En Cuaderno de Pedagogía, Vol. IV, № 9. Laborde, Rosario.

Salas, R., compilador

2005 Pensamiento Crítico Latinoamericano. Conceptos Fundamentales. Universidad Católica Silva Henríquez, Santiago.

Walsh, C.

2002 (De) Construir la interculturalidad. Consideraciones críticas desde la política, la colonialidad y los movimientos indígenas y negros en el Ecuador. En Interculturalidad y Política. Desafios y Posibilidades, editado por N. Fuller, pp. 115-142. Red para el Desarrollo de las Ciencias Sociales en el Perú, Lima.

\section{Notas}

1 La Corporación Nacional de Desarrollo Indígena, Conadi, participó también en los planes piloto y actualmente deberá liderar la "Fase II" del Programa Orígenes, sin embargo nuestros análisis se centran mayoritariamente en los discursos, acciones y concreciones emergentes en el contexto de implementación de la Educación Intercultural Bilingüe, EIB, por el Ministerio de Educación, organismo que ha tenido un rol más protagónico en las primeas fases de institucionalización de ésta. La implementación del componente de educación del Programa Orígenes, principal política pública de la EIB en Chile, vino a su vez a consolidar esta implementación. Su implementación se realizó de manera centralizada desde el Ministerio de Educación (Secreduc en lo regional operativo), institución estatal encargada de seleccionar las 27 escuelas de la Región de Los Lagos en que se desarrollaría la educación intercultural bilingüe. Tanto Mineduc como Conadi, en tanto instituciones del Estado, legitiman las políticas estatales que se establecen para la población indígena, sin embargo, tienen dinámicas distintas, probablemente derivadas de las particulares historicidades de cada una y de su mayor o menor centralismo.

2 En mapuche futa o fucha 'grande'; willi o huilli 'sur' y 'mapu tierra' o 'territorio' = "Grandes Tierras del Sur". Este territorio corresponde en gran parte a las actuales regiones de Los Ríos y de Los Lagos.

3 La Ley Indígena establece, de manera especial, una serie de "Disposiciones Particulares Complementarias para los Mapuches Huilliches" en las que se les reconoce de manera explícita su "sistema tradicional de cacicados y su ámbito territorial" y se dictamina que "Las autoridades del Estado establecerán relaciones adecuadas con los caciques y sus representantes" en todos aquellos asuntos vinculados con Áreas de Desarrollo Indígena, y con Reconocimiento, Respeto y Protección de las Culturas Indígenas.

4 De acuerdo con Cox (2005:37) el "mejoramiento de la calidad de las oportunidades de aprendizaje" es el objetivo central de la agenda educacional de los gobiernos democráticos.
5 Foucault (1992) señala estas características para el principio del autor.

6 Respecto de los tipos de dependencia de los establecimientos, de acuerdo con González, P. "Existen cuatro formas de gestión distintas en el sistema escolar chileno: municipal; particular subvencionada por el Estado; particular pagada (sin subvención estatal), y corporaciones empresariales que administran establecimientos educacionales de propiedad fiscal" (Cox 2005:597).

7 El asombro y perplejidad que provoca la visión de lo moderno, evoca la interpretación que hace Berman, M. (2000:146155) del poema "Los ojos de los pobres" de Baudelaire. En ambos casos, el vislumbre de la otra orilla del abismo no acerca, sino que hace más evidente la dramática amplitud de la distancia.

8 Vicecacique.

9 Un desarrollo más amplio sobre la ahistoricidad del currículum lo trata Sandra Corazza, en Moreira (1997).

10 Wetripantu significa literalmente we 'nuevo'; tripan 'salir'; antu 'sol' = "Nueva Salida del Sol". Corresponde al año nuevo de todos los pueblos originarios del hemisferio sur. Esta celebración tiene que ver con la interpretación y comprensión que los antepasados mapuche hicieron del cambio que se produce en la Tierra en su relación con el Sol y la Luna, que ocurre entre los días 20 y 25 de junio de acuerdo al calendario occidental. Para el pueblo mapuche, el wetripantu es la renovación de la naturaleza en su relación armónica entre sus elementos y, a su vez, la renovación y ratificación del fortalecimiento del tronco familiar. En el ámbito científico, este cambio se conoce como el solsticio de invierno que acontece en el momento en que el polo sur se encuentra más alejado del astro solar. La cultura occidental celebra el año nuevo el primero de enero, debido a que en el hemisferio norte el solsticio de invierno se produce durante el 20 y 25 de diciembre de cada año (Diario Austral de Valdivia 2004).

11 Ñukemapu de ñuke 'madre'; y mapu 'tierra' = "Madre Tierra", forma parte intrínseca del ser mapuche: de mapu 
' tierra' y che 'gente' = "Gente de la Tierra". Del Portal UMCE en línea extraemos "Antes de la peluca y la casaca / fueron los ríos arteriales: / fueron las cordilleras, en cuya onda raída / el cóndor o la nieve, parecían inmóviles, / fue la humedad y la espesura, el trueno/ sin nombre todavía las pampas planetarias". / (Neruda, Pablo, Obras Completas, 1962:297). La tierra madre genera una imagen a la cual se siente unido el hombre. Con belleza y poesía lo cuentan las naciones indígenas y con sabiduría lo viven. La madre tierra no puede ser dividida: "en la mapu no existe división geográfico-política. La tierra mapuche con su cuerpo de tradiciones inherentes, es en lo sustancial, la misma, o toda una, para Chile y Argentina. Nada divide el accidente cordillerano". (Koessler, Bertha, 1962, p. XX). Y es necesario estar en contacto con la madre, "solamente quien la toca con los pies desnudos está verdaderamente unido a nuestra
Ñuke Mapu, que nos da la vida desde el principio hasta el fin. ¡Buena papai es! (...) Papai es el nombre que los hijos dan a la madre y, en general, se da a las mujeres de mayor respeto, por lo común las más viejas". Balart y Cesped (s/f).

12 Efku consiste en un ritual en el que se coloca al centro un brasero ceremonial, al lado de una rama de laurel u otro árbol sagrado. Cada persona que participa quema alimentos secos en el brasero o Kütral para contactar a las divinidades y espíritus ancestrales mapuche-huilliches, a quienes se les agradece y pide, generalmente en voz alta, ya sea en castellano o chedugun. Se realizan asperciones de alimentos líquidos, especialmente muday en el árbol sagrado, mientras se continúa agradeciendo y o solicitando. Cada persona participante va esperando su turno para realizar el ritual, el Lonko o la Maestra de Ceremonias indica a cada cual su momento de participación. 